\title{
Information Literacy in the Sciences: Faculty Perception of Undergraduate Student Skill
}

\author{
Heather Brodie Perry
}

\begin{abstract}
Academic librarians need reliable information on the needs of faculty teaching undergraduates about seeking and using information. This study describes information gathered from semistructured interviews of teaching faculty in the sciences from several Boston-area colleges. The interview results provided insight into science faculty attitudes toward student research skill and ability. Faculty articulated what they wanted from students seeking research articles, including finding where the gaps were. They described their concerns about threats to research integrity including conflicts of interest and Open Access publishing. Study results will prove useful for librarians trying to better serve the needs of their science faculty.
\end{abstract}

In a recent lecture, Paul Sturges recounted a story about the gap between perception and user needs, which inspired this study. A development organization in Zimbabwe created toilets for a village; returning to the village some time later, they discovered they had been converted to grain stores. ${ }^{1}$ The development experts perceived a need for toilets, but the villagers needed grain stores, an error easily avoided by asking users about their needs. Instruction librarians sometimes make the same type of error. Librarians can approach information literacy instruction with their own perception of the type of instruction the students need without fully understanding the needs of faculty or students in the discipline. Additional information about what faculty expect from instruction will assist librarians in providing students with disciplineappropriate instruction.

Information literacy (IL) is viewed as an essential skill for college students; it is defined as "a set of abilities requiring individuals to recognize when information is needed and have the ability to locate, evaluate and use effectively the needed information." ${ }^{2}$ The IL competencies can be seen as generic skills, consistent across disciples or specific skills within a disciplinary lens. The standards themselves use both the language of universality and discipline specificity. ${ }^{3}$ While the best way to achieve IL competency for students is through collaboration between disciplinary faculty and librarians, collaboration is not always seen in all situations. ${ }^{4}$ The Association of College and Research Libraries has recently developed the Frameworks for Information Literacy

${ }^{*}$ Heather Brodie Perry is Reference Librarian, Assistant Professor at Stonehill College and a PhD Student at Simmons College; e-mail: hperry@stonehill.edu. (2)2017 Heather Brodie Perry, Attribution-NonCommercial (http://creativecommons.org/licenses/by-nc/4.0/) CC BY-NC. 
for Higher Education to provide a framework of richer core ideas to facilitate better collaboration with faculty for the acquisition of information literacy in students. ${ }^{5}$ While the Frameworks were not in place when the interviews for this study were conducted, it is interesting and informative for librarians to look at the faculty members; perceptions of information literacy gaps through the lens of the frameworks.

Research has found that different disciplines use different information-seeking behaviors, ${ }^{6}$ with scientists differing from scholars in other disciplines. Librarians need to be aware of the differences between disciplines to effectively prepare students to become information-literate in their disciplines. Research has found that discussions of information literacy often use language that seems to exclude the sciences and may discourage faculty who may not recognize the benefits of IL. ${ }^{7}$ A survey found that science and engineering faculty recognize that they need discipline-specific instruction, stating, "[1]ibrarians involved in instructional activities must come to know individual disciplines, departments, and programs because all have slightly different expectations and needs." 8 The ACRL developed the Information Literacy Standards for Science and Engineering/Technology in 2005 to address these disciplinary differences. ${ }^{9}$

While literature indicates that the disciplines are different, there are few library studies that have specifically asked faculty about their disciplinary needs. ${ }^{10}$ The studies find there are distinctions, but they lack detail about what faculty are interested in seeing from undergraduate bibliographic research. This study sought a deeper understanding of the elements of information literacy that science teaching faculty want from their students and the support that they desire from the library. The study explored whether or not faculty believe that undergraduate students have sufficient skill to fully understand the literature they were accessing through searching and what the implications of their skill gaps are. The study endeavored to determine if science faculty had concerns about the influence of funding source on the conduct and publication of research and if students had sufficient skill to critically evaluate research for bias.

\section{Research Questions}

While previous research provides some insight into faculty perspectives on the type of information they use, this study adds to the growing body of knowledge. Specifically, this study explored five research questions:

1. What is the expectation of science faculty regarding their students' use and evaluation of the scientific literature? What types of literature do they require their students to consult when performing literature research?

2. What is the faculty's perception of the effectiveness of students' searches, the literature they retrieve and select? Where are the gaps in their knowledge and skills?

3. What kind of instruction do students receive, and do they receive instruction from the faculty, librarians, or both?

4. Do faculty members perceive that students have sufficient skill to effectively evaluate research?

5. Do faculty members express concerns about research funding and its impact on research integrity? Do students have sufficient knowledge and ability to critically evaluate research that may have been influenced by a conflict of interest?

\section{Literature Review}

\section{Introduction}

Academic librarians have looked to information literacy as a way to align the library with the curricular goals of the institution. There is little in the LIS literature addressing the specific needs of science faculty in developing the information literacy skills of 
students in their discipline. A better understanding of the perspective of faculty will assist librarians in instructing students outside their area of expertise.

Much of what we know about information literacy in the sciences is from the librarians' perspective rather than from the faculty perspective, although there are articles describing individual collaborations between faculty and librarians. ${ }^{11}$ Librarians at the University of Maryland Baltimore County determined the baseline information literacy levels of incoming first-year students with an instrument based on the five Association of College and Research Libraries (ACRL) Standards (2000). ${ }^{12}$ Their survey results were primarily from biology students; the survey found that students report a high level of comfort seeking information, and prefer to get the information on the web. ${ }^{13}$ The researchers' data confirmed that students overestimated their searching skills and their ability to evaluate sources. ${ }^{14}$ While the students expressed high levels of comfort developing searches, the researchers found they were unfamiliar with basic search concepts including Boolean operators, truncation, and controlled vocabulary and had difficulty identifying citations for different types of search results. ${ }^{15}$ Additionally, while expressing confidence in their evaluation skills, the students selected web sources more often than peer-reviewed articles. ${ }^{16}$

\section{Instruction}

A nationwide survey of librarians found that librarians tailored their instruction to their perception of faculty expectations, yet there was still a disconnect between faculty and librarians' expectations over information literacy and library instruction. ${ }^{17}$ The survey suggested that librarians may not be devoting the time to and emphasis on topics that are most relevant to faculty. ${ }^{18}$ Faculty may feel that they are better suited to instruct their students in the information literacy skills they consider essential than the librarians. Saunders found that the onus of the responsibility was on the librarian to initiate and maintain a relationship with faculty to facilitate integration of IL. ${ }^{19}$ One survey respondent suggested that librarians spend more time on evaluation and promoting skepticism of information and sources. ${ }^{20}$ This study provides insight into the needs of disciplinary faculty when promoting information literacy instruction.

The Information Literacy Competency Standards for Higher Education developed into the Frameworks for Information Literacy for Higher Education to better respond to the rapidly changing information landscape. ${ }^{21}$ The Frameworks encourage librarians to reach out to faculty to form beneficial partnerships. The Frameworks acknowledge that faculty have the responsibility of engaging students with the core competencies and scholarship of their disciplines while also encouraging librarians to take responsibility for engaging students in information literacy activities that align with their discipline. ${ }^{22}$

Although many librarians find the use of one-shot library instruction to be insufficient to fully deliver the requisite content to students, several studies have found that single-session library instructions have a positive impact on the acquisition of information literacy skills. ${ }^{23}$ Some librarians have the advantage of becoming embedded librarians, where they partner with a faculty member in course design and implementation. The experience of embedded librarians varies, but the collaboration typically enables the librarian to have an impact on student information literacy skill acquisition. Pritchard found that it is essential for librarians to reach out and establish relationships with faculty. ${ }^{24}$ These relationships can be made easier by having expertise in the discipline as well as an understanding of the language and terminology of the field. Relationships need to be actively pursued and demonstrate the contribution that librarians can make to support student learning. ${ }^{25}$

Several studies describe the experiences of librarians collaborating with faculty in the sciences to implement information literacy in their courses. Indiana University explored 
the integration of information literacy within specific disciplines and collaborated with biology professors to align information literacy with course learning outcomes. ${ }^{26} \mathrm{IL} \mathrm{com}$ petencies were embedded into an upper-level biology course by a partnership between a faculty member and a librarian. ${ }^{27}$ The librarian co-taught the course, which required the students to gather, evaluate, and synthesize information to augment and enhance achievement of disciplinary learning objectives. ${ }^{28}$ They found that students expressed a considerable increase in self-reported ability to find, read, and use scientific research. ${ }^{29}$

\section{Evaluation}

One area of evaluation that is not well covered in the LIS literature is the issue of bias in research. The prevalence of financial conflict of interest (FCOI) is a well-recognized issue in the medical and biomedical fields but is less well covered in other disciplinary literatures. As the corporate funding of research has increased over the past two decades, so have relationships between industry and academic institutions. ${ }^{30}$ Conflict of interest (COI) exists when the primary interests of researchers are impacted by a secondary interest, especially financial gain. ${ }^{31}$ Financial conflicts of interest can influence scientific research in important ways including selection of questions studied, research design, conclusions presented, and research published. ${ }^{32}$ The ACRL IL Standards for Science and Engineering, Standard 3 Performance Indicator 2 does seem to indicate that an understanding of this issue was considered by the authors of the Standard. ${ }^{33}$ Peer review is the model that is widely expected to be the gatekeeper for ensuring the quality of scientific publishing. ${ }^{34}$ While there have been notable recent failures of the peer-review system, ${ }^{35}$ it is the current mechanism for evaluating research before publication. This study sought to investigate if faculty believed that students had sufficient skill to evaluate research for bias.

\section{Method}

\section{Participants}

From May to July 2015, eighteen interviews were conducted with faculty from seven Boston-area colleges. Faculty were recruited from the faculty directories of the colleges. Faculty in Biology, Chemistry, Nursing, Nutrition, Neuroscience, Physics, and Geology, as well as those listed under College of Sciences, were selected for inclusion. Respondents were recruited by e-mail, and all volunteers were interviewed. The sample was composed of self-selected faculty at all levels, from adjunct instructors to full professors. Five of the colleges were four-year institutions, and two taught undergraduates as well as graduate students. All of the interviewed faculty taught undergraduate students. Interviews were conducted by phone, e-mail, or in person by the author.

\section{Procedure}

Semistructured interview questions were asked of all of the participants. The informal nature of the interviews provided the respondents latitude in response and enabled the interviewer to explore and clarify interesting perspectives. Interviews lasted from 30 minutes to 2 hours. This enabled the interviewer to cover the essential questions, with the flexibility to elaborate on themes of interest to the respondents.

\begin{tabular}{|l|c|}
\hline \multicolumn{2}{|c|}{ TABLE 1 } \\
Faculty Disciplines (n=18) \\
\hline Chemistry & 3 \\
\hline Biochemical Engineering & 1 \\
\hline Biology & 6 \\
\hline Nursing & 3 \\
\hline Ecology & 2 \\
\hline Geology & 1 \\
\hline Biochemistry & 1 \\
\hline Neuroscience & 1 \\
\hline
\end{tabular}


The interviewer took extensive notes during the interviews, transcribing interesting quotations and categorizing themes. Following each interview, the notes were categorized, by theme and by question addressed. Also categorized were issues that arose during the interviews that the interviewer did not expect. Patterns were discovered between answers to different questions and across the disciplines of the interviewees. Several themes emerged among the responses.

\section{Results}

The objective of this study was to gain further insight into the specifics of what faculty want to see when their students do library research. The results of the questions asked clustered around five themes: 1 ) what faculty expect from student literature searches; 2) the gap between student performance and instructor expectations; 3 ) the instruction that students receive about the scientific literature; 4) the perception of the level of student evaluation skill; and 5) concerns about research integrity. An additional theme emerged unexpectedly in the interviews concerning Open Access (OA) publishing. As much of the literature on OA focuses on its benefits, this researcher did not anticipate that concerns about $\mathrm{OA}$ would arise and did not include the issue in the original question set. As it became clear that this was a concern, a question was added to the protocol.

As librarians are using the Frameworks ${ }^{36}$ to inform their instruction, the findings of this study could provide greater understanding of the disciplinary needs of science faculty. The responses to the question areas informed all of the six frames: Authority Is Constructed and Contextual, Information Creation as a Process, Information Has Value, Research as Inquiry, Scholarship as Conversation, and Searching as Strategic Exploration. ${ }^{37}$ As the frames represent the lens through which librarians will be instructing students in IL, they may provide librarians with a better way to collaborate with faculty to provide students with expected disciplinary IL skills.

\section{Literature Searches}

The first set of questions concerned what faculty want to see when students do literature searches in their field. Ninety-four percent of respondents specifically mentioned that they want their students to find primary research articles. Many additionally stressed the need for these articles to be from relevant, high-quality, peer-reviewed journals. Nursing professors stressed the need for students to find evidence-based literature. Respondents explained that the ability to work with the literature was developed over time, and 22 percent responded that they had lower-level students begin their research with background information and other more accessible literature before moving on to primary research. They recommended that the students begin with secondary sources, their textbooks, and even Wikipedia to become familiar with the topic before moving on to more sophisticated research. Respondents stated that they wanted students to understand that different literature serves different purposes. One said s/he wanted students to "use research to expand their knowledge and find new references." Faculty wanted students to focus on literature they could understand, and they could relate to what they are doing in the classroom.

There was no consensus around the tools faculty wanted their students to use to find articles. Responses varied from the appropriate disciplinary databases to Google Scholar. Some faculty expressed interest in learning more about the specific tools that were available. The database that was most frequently mentioned was PubMed. Respondents did not typically limit students to specific journals; 28 percent gave students some suggestions or recommendations of strong journals in the discipline. Faculty in the sciences were interested in having students develop strong skills reading and working with primary literature. 


\section{Information Literacy Gaps}

The second question set explored the gaps between what faculty expect from students, what they see demonstrated, and their efforts to bridge the gaps. One of the respondents stated that the students met expectations, while 66 percent of respondents stated that their expectations were sometimes met and 29 percent said their expectations were not, or rarely, met. Faculty explained that developing skills in this area was a process and that students "need lots of practice." They suggested that students need to develop their critical thinking skills and be willing to ask questions. The faculty described this process of developing as part of the expected trajectory, explaining that many of the skills they like to see are not developed until graduate school.

The students failed to meet faculty expectations in several ways, with respondents mentioning several areas in which they felt the students fall short. The area in which students most commonly fell short was in the evaluation of sources, often selecting sources that were inappropriate or lacking in rigor (50\%). Additional concerns mentioned were: inability to differentiate primary from secondary sources $(33 \%)$, time management (28\%), lack of perseverance (28\%), lack of sufficient critical thinking skills $(22 \%)$, and inexperience (22\%). Professors were very specific that time management was a significant gap. Students' lack of experience in doing research assignments contributed to their underestimating the amount of time it would take to complete the research. When they did their research, they often did it poorly because of time constraints. The six categories in which there were gaps between expectations and performance were all areas where students received instruction and support to improve their skills.

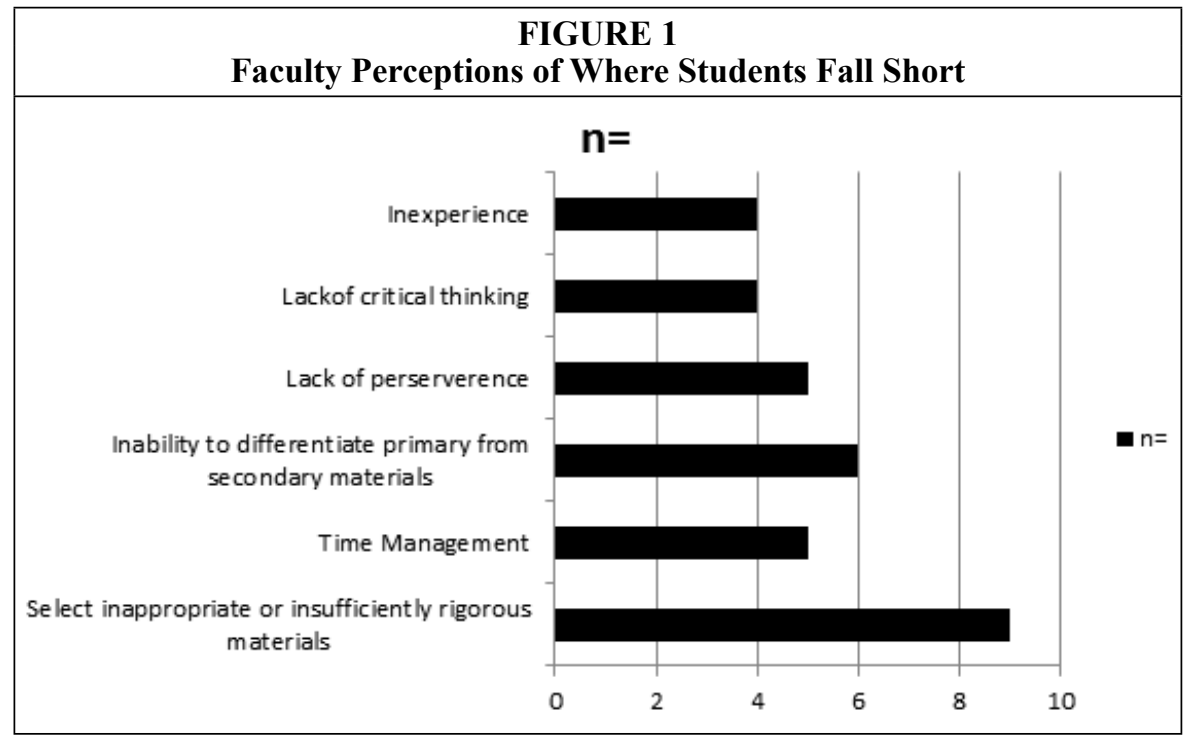

Students' inability to effectively evaluate sources was the most common concern. Several faculty mentioned that students simply selected the first thing they found that they felt was appropriate, but they had a hard time looking at it critically. One said that students "can't sort the relevant from the irrelevant." Another said that "they select articles they don't understand." Faculty members suggested different methods to give them time and experience developing these skills. Some had specific classroom instruction that they conducted; others had librarians come to instruct their students. One stated that the students should receive instruction from the librarians at the li- 
brary. Inability to differentiate primary from secondary sources was an important area of concern. Some students had a hard time determining if an article was a primary research article, a review article, or even a journal article.

Issues related to time management were mentioned by several faculty and included behaviors that are likely familiar across disciplines. Faculty mentioned that students do not give themselves enough time to do the assignment well. They start the project late and if the relevant information is not available locally, there is not enough time for interlibrary loan. Faculty mentioned that students became frustrated when the answer is not found immediately. They explained that students did not give themselves enough time to engage with the literature. One faculty member specifically mentioned that students would quickly say that they could not find anything or could not do the assignment, without putting time into trying to work out the problem themselves. Faculty indicated that students did not see research as a process, where they would return to their searching as they progressed through the course of their assignment. One faculty member expressed frustration with the common experience of having students embrace the first thing they find and be unwilling to modify or refine their question through further research.

\section{Instruction}

Faculty used a variety of techniques to assist students with their research skills. One respondent specifically mentioned that this was the domain of the librarians, but the remainder provided some level of instruction. Instruction provided by the faculty varied widely, from limited class time spent on developing research skill, to multiple in-depth activities across the semester to engage students deeply in the literature. Interesting examples included having students read a piece of literature and developing questions about the article to explore more deeply, and finding studies that build upon the research the students are doing in the lab. The role of the literature within the course also varied, from courses where little research was done, to courses centered on reading and working with the primary literature. Other faculty described having students use chaining to explore the literature around an article of central concern. Coaching students through the iterative process of research was a recurring theme.

The techniques that many faculty used to help students were reminiscent of Vygotsky's Zone of Proximal Development. ${ }^{38}$ A variety of techniques were described centering on the approach of creating a bridge between what the students know and the skills they are expected to develop. Many described a situation where initially students work with faculty or peers, and, after working with more basic literature, they can do more complex work independently.

Faculty reported using a variety of techniques with in-class exercises being used by 50 percent of respondents. Twenty-eight percent used model articles to assist students with understanding how to approach the literature, 17 percent used scaffolded assignments in which students had multiple opportunities for feedback, and 17 percent taught students how to read scientific papers and how to skim effectively. Thirty-three percent had librarians participate in instruction.

\section{Student Understanding of Research}

The fourth question set explored the faculty perception of the level of student understanding of the articles they are reading. Three questions delved into the faculty perception of the student skill level:

1. Would students be able to recognize and discard studies with methodological flaws?

2. Would students be able to determine whether the conclusions that were presented follow from the study results? 
3. Would students have sufficient knowledge of statistics to fully understand the research they are reading?

The researcher was interested in understanding if students possessed the necessary knowledge to critically evaluate the research articles.

The question "Would students be able to recognize and discard studies with methodological flaws?" received an almost unanimous "no" from responding faculty. However, some faculty qualified their response by saying that some advanced students may have developed this skill. Additionally, several explained in depth why they felt that their students have not attained this level of ability. Many mentioned that this was a very advanced skill and could not be expected of undergraduates. This response brings up an interesting question of what undergraduates are expected to understand about primary literature and what students are expected to uncover when evaluating the literature.

Several mentioned that they felt students did not feel qualified to question research and researchers. One exception mentioned was that some students did feel qualified to suggest that a sample size was too small. Faculty often expressed that critiquing research was an advanced skill that students would not develop until graduate school. One respondent felt that peer review should ensure that studies with methodological flaws were not published, but three others specifically mentioned that sometimes even peer reviewers miss studies with flaws. The existence of the retraction watch website $^{39}$ attests to the difficulty of catching all flawed research. The consensus was that only the most capable, advanced students were able to recognize methodological flaws in studies.

The question "Would students be able to determine whether the conclusions that were presented follow from the study results?" was answered slightly more optimistically. Twenty-two percent of respondents felt that students were developing the skills to determine if the presented conclusions were an overreach from the study results. While the majority felt that the students were still developing the skill, the faculty were actively working with students to encourage its development. Many stated that they felt students would likely develop the skill by the completion of their degree.

In answering the third component of this question, "Do you believe that your students have sufficient knowledge of statistics to fully understand the research they are reading?" the respondents said that statistical knowledge and ability varied considerably. They expressed a lack of knowledge about the students' background in statistics. Others said that it varied widely with the students. Some mentioned that some of the statistical tests used in research were beyond even faculty knowledge. While most stated that students had at least some statistics by the time they were advanced students, it was unknown whether this was sufficient.

\section{Research Integrity}

The fifth area of questioning involved issues of research integrity, including conflict of interest. There was a broad range of concern about the issue of COI, with 72 percent of respondents stating that they had some level of concern about the impact of COI on research integrity. Results varied from the 28 percent who felt it was not a problem at all to the 11 percent who found it to be such a serious concern that a major portion of course time in at least one of their courses was devoted to discussion of issues around COI. Between the two extremes, the remainder had some degree of concern about COI, although some felt it was not much of an issue in their discipline but could be an issue in related fields. Several mentioned that their personal research was basic research more likely to receive National Science Foundation (NSF) or the National Institutes of Health (NIH) funding than corporate funding. The respondents with limited concern discussed it in their class very briefly and addressed questions when raised by stu- 
dents. When asked whether they have concerns about researchers performing research funded by corporations, faculty again varied in the level of concern. Some (33\%) felt there were adequate controls to ensure that conflict of interest would not impact research and that research with conflicts would not be published. One even mentioned that "universities go to great lengths to prevent researcher conflicts." Most hoped that there were strong controls, but they recognized the potential for conflict. Many (22\%) recognized the importance of funding to get research done and the delicate balancing act this required. Others (11\%) mentioned that the main funding for their discipline was the NSF or the NIH and saw this as having a smaller potential for conflict.

\section{Open Access Publishing}

Although there were no questions on the interview protocol about journal publishing, the issue of open access emerged unexpectedly from the interviews. The participants expressed serious concerns about open access (OA) publishing, although they did not always use the specific terminology. Although the first few interviewees did not explicitly describe concerns with OA, it is not known if they simply did not express these concerns because no question about publishing was asked. Concerns about OA were strongly held. Several participants described the number of solicitations they received in their e-mail for requests for papers; many were from journals that did not even publish in their area of research, or published in such broad areas that nearly anything would fit the scope of the journal. They expressed concern about the quality of the peer review performed for these journals and about the quality of peer review among OA journals in general. They expressed a lack of certainty about the level of rigor. Several mentioned the names of high-quality OA journals, such as PLOS One, but stated doubt that all were similarly rigorous. Several expressed concern for students using OA journals because they believed that students tend to accept everything as fact, lacking the willingness to be critical.

\section{Frameworks for Information Literacy}

While the study was conducted before the Frameworks for Information Literacy were published, they do provide a way to more closely align science faculty's disciplinary needs with Information Literacy instruction. It is interesting to see where the gaps that faculty perceive in their students' learning falls within the frameworks. The science faculty in this study were far more concerned with a student's ability to critically evaluate information than they were with the mechanics of search. The Frameworks may provide librarians a useful mechanism for better filling the disciplinary needs of faculty members.

\section{Authority Is Constructed and Contextual}

The frame "Authority is Constructed and Contextual" stood out as one of the most important frames for the gaps that the faculty were most concerned about. Faculty overwhelmingly expressed concerns with the critical thinking skills of students and their inability to evaluate the sources that they are reading. This frame is also important because faculty stressed the importance of finding and working with the primary literature. While the frameworks do not specifically address primary literature, I believe that the history of scientific research has constructed the primary research study as the way in which scientific research is conducted. While there are other ways in which information is transmitted, the most important means of transmitting scientific knowledge between scientists is the primary study. 
laborate with science faculty on developing student research skills. While faculty want students to read the primary literature, recognizing that different types of literature serves different purposes can be instrumental in providing students with bridges to the primary literature. Librarians can assist students with finding information they can understand and guide them through the process of using this literature to move them on to more sophisticated research as they become more skilled. Some of the faculty did mention encouraging students to use sources like Wikipedia, textbooks, or review literature to move them toward the primary literature. Other faculty recognized that different types of literature serve different purposes in assignments and were appropriate for different audiences. A nursing professor explained that, when doing patient information in the clinic, students would want to use authoritative secondary or tertiary sources written at the patient's level, rather than the primary literature, to fill the patient's information need. Faculty stressed the importance of students recognizing the distinctions between different types of information.

\section{Information Has Value}

In an information society, information has value as a commodity and as a means of influence. The frame "Information Has Value" intersects with faculty concerns about research integrity and with OA publishing. The issue of research integrity and concerns about conflict of interest attest to the intrinsic value of information, as financial concerns can lead to the distortion of information. Much of the LIS literature focuses on the benefits of OA publishing, so increased understanding among librarians of the concerns that faculty have with OA could prove beneficial. This aligns with the needs for students to be able to critically evaluate information to determine which information is suitable for their information need and which information may be corrupted by financial interests.

\section{Research as Inquiry}

One gap that faculty commented on was student failure to see research as a cognitive process instead of a hurdle to get over. Faculty wanted students to engage with the literature and delve deeply into important questions. Instead, they found students truncating the process rather than fully exploring the literature and following new questions as they arose. Faculty expressed the belief that this was a skill to be developed through time and experience.

\section{Scholarship as Conversation}

The frame "Scholarship as Conversation" speaks directly to the priorities of science faculty as they see the scientific conversation taking place through primary research. Becoming familiar with the methods of scientific communication will assist developing students in joining the scientific conversation. The faculty mentioned wanted students to use chaining to follow research through the process of citing and being cited to build on the knowledge that has gone before them.

\section{Searching as Strategic Exploration}

Faculty did not have many concerns about students' technical searching skills; rather, they were concerned about students' lack of perseverance. Faculty wanted students to see searching as iterative and be willing to persist even when they encountered difficulties. Faculty wanted students to learn from the literature they read, follow questions that arose, and pursue new areas of inquiry.

\section{Discussion}

Integrating information literacy into the curriculum continues to be a challenge for 
many academic librarians. For faculty to be receptive to librarians' instruction efforts, they need to have confidence that librarians are responding to their disciplinary needs. This study found that 94 percent of responding faculty specifically mentioned primary sources; they found that the most significant area in which students fail to meet faculty expectations is in evaluation of sources. The interviews indicated that faculty are more concerned with students perfecting the intellectual skills of evaluating the literature to find the best sources rather than concentrating on the more technical skill of performing searches. This research indicates that librarians working with science faculty may need to tailor their instruction to more closely match the needs of science faculty, concentrating on the higher-level cognitive skills rather than technical searching skills.

Many faculty noted that the students were willing to accept everything they found as true. They stated that students lacked critical thinking skills and suggested that students felt that they "did not have the right to question" the research they found. This raises interesting questions regarding student thinking about research. Is it that they cannot differentiate between good-quality research and poorer-quality research, or is it that they feel they should not question the quality of published research? Are students intimidated by the affiliations of article authors and feel unqualified to raise questions about the research they read? One respondent mentioned that students had difficulty in evaluation because "they do not have an area of expertise."

One interesting question emerging from reviewing the responses is this: do faculty expect that students will question the literature? The way the interviewer posed the question, "would students be able to recognize, and discard studies with methodological flaws?" may have implied that this is expected. Better question formulation may have resulted in clearer responses. This leads to interesting implications for instruction. Specifically, are faculty and librarians in agreement with what it means for students to be able to evaluate literature?

Three faculty members (17\%) specifically stated that they wanted students to be able to "critique" the research, and one had students create questions while they were reading the research to further explore in class discussion. Conversely, one said that the quality of research was "not for students to determine." The ability of students to effectively evaluate research is an area for additional research. Since faculty interviewed taught undergraduates at all levels, the expectation of students to be able to skillfully critique research may vary with academic level. Understanding faculty expectations of student evaluation skill has important implications for library instruction, as well as librarians interacting with students during reference interactions.

The emergence of the issue of concerns with OA publishing raises important questions about communicating with faculty, as well as interacting with students using $\mathrm{OA}$ journals. The issue of OA is well discussed in the library literature, but much of the literature focuses on the advantages of OA in its ability to increase access rather than the potential for negative consequences of increased access to lower-quality research. Suber suggests that the vast quantity of information with OA will enable the body of literature to dilute the dreck ${ }^{40}$ with high-quality literature. There have been some concerns discussed, ${ }^{41}$ and a list of questionable publishers is maintained. ${ }^{42} \mathrm{OA}$ is likely to be an area of continuing research. The level of faculty concern about OA was not expected by this researcher, indicating that future research about faculty perceptions and use of OA is warranted if libraries hope to promote OA. It is likely that issues around OA may be discipline-specific, and disciplinary librarians should be aware of these concerns.

\section{Limitations of the Study}

The faculty self-selected for participation in the study, so it is not a random sample 
of faculty members. As the study was performed in the summer, many faculty were away from their institutions. which may have led to decreased participation. The study was also geographically limited, as all participants were from the Boston area, an area with a dense concentration of colleges and universities; this may impact the types of responses given. Due to the specialized nature of this study sample, these results may not be generalizable.

\section{Conclusion}

This study provided information and insight into what faculty are looking for when their undergraduate students are doing literature searches and evaluating their search results. Greater insight into the needs and wants of faculty can assist librarians in providing better instruction to patrons. The research indicated that librarians should focus on primary literature when working with students in the sciences. Additionally, librarians should be aware of the difficulties students encounter when working with the primary research, from recognizing it to evaluating it, to reading and understanding it.

Increased emphasis on the evaluation of scholarly literature should also be considered, as this is an important skill gap. As faculty suggested that students believe everything they read, establishing an appropriate level of skepticism in undergraduates is likely an important issue. While instructing students in finding and evaluating the literature was important to the faculty in the study, only 33 percent used librarians in the classroom for instruction. Faculty were not asked why they used or did not use librarians in instructing their students, but it would be an interesting topic for further research. Discovering why faculty did not use librarians in the classroom would benefit librarians in developing further collaborations with teaching faculty.

While the issue of COI and concerns about research funding were not taught by the majority ( $89 \%$ ) of faculty interviewed, the study indicated that this issue was a concern at some level for 72 percent, and a serious concern for 11 percent, warranting additional study about this issue. Given the considerable body of evidence of the importance of the issue in the biomedical literature and the level of concern about the issue in this sample of faculty, more research on this topic and its inclusion in information literacy instruction is indicated.

The issue of Open Access publishing, which revealed itself during the interviews, was a significant concern to the faculty raising the issue. While some mentioned the benefit of increased availability of research, they had serious concerns about the quality of peer review and the quality of the research being published. Librarians should be aware of some of the concerns faculty have about OA journals and their students' ability to evaluate this material. Two respondents were highly interested in the OA issue after a speaker came to campus, suggesting the potential impact of library-sponsored educational programs.

While this study provides some insight into what science faculty want from their students, there is no substitute for working with individual faculty to gain insight into their specific needs. The faculty in this study indicated several areas in which librarians could assist in the growth of science students' information literacy skills. This study indicated that there is a gap between the skills faculty want students to bring to their literature searches and the skills the students frequently exhibit; librarians can help in bridging the gap. 


\section{APPENDIX A. Questions: Faculty Perceptions of Student Library Research}

What do you want your students to look for when looking for research articles?

Do your students meet your expectations when looking for research?

- If they do not meet your expectations, how do they fall short?

- If so, what type of instruction do you give them?

- Do you advise them to use any specific tools or databases?

- Do you recommend any specific journals?

What do you wish that students knew about doing bibliographic research?

Would students be able to recognize and discard studies with methodological flaws? Would students be able to determine if presented conclusions follow from the study results?

Do you believe that your students have sufficient knowledge of statistics to fully understand the research they are reading?

What attributes do you consider to be essential components of information literacy in your discipline?

Do you discuss the issues of conflict of interest or study funding with students? If yes, what do you discuss?

Do the students in your discipline research issues that are likely to have issues with conflict of interest?

- What areas might they see conflict of interest in?

Do you have any concerns about researcher conflict of interest, or influence of funding source on the quality of research?

\section{Notes}

1. Rodney Paul Sturges and Richard Neill, The Quiet Struggle: Information and Libraries for the People of Africa (Burns \& Oates, 1998).

2. American Library Association, Information Literacy Competency Standards for Higher Education (2000), available online at www.ala.org/acrl/sites/ala.org.acrl/files/content/standards/standards. pdf [accessed 13 August 2016].

3. Kate Manuel, Susan E. Beck, and Molly Molloy, "An Ethnographic Study of Attitudes Influencing Faculty Collaboration in Library Instruction," Reference Librarian 43, no. 89/90 (2005): $139-61$.

4. Ann Grafstein, "A Discipline-based Approach to Information Literacy," Journal of Academic Librarianship 28, no. 4 (2002): 197-204.

5. Association of College and Research Libraries, "Framework for Information Literacy for Higher Education," available online at www.ala.org/acrl/standards/ilframework [accessed 13 August 2016].

6. David Ellis, "Modeling the Information-seeking Patterns Of Academic Researchers: A Grounded Theory Approach," Library Quarterly (1993): 469-86.

7. Manuel, Beck, and Molloy, "An Ethnographic Study," 139-61.

8. Gloria J. Leckie and Anne Fullerton, "Information Literacy in Science and Engineering Undergraduate Education: Faculty Attitudes and Pedagogical Practices," College E Research Libraries 60, no. 1 (1999): 9-29.

9. The ALA/ACRL/STS Task Force on Information Literacy for Science and Technology, Information Literacy Standards for Science and Engineering/Technology (2016), available online at www. ala.org/acrl/standards/infolitscitech [accessed 13 August 2016].

10. Laura Saunders, "Culture and Collaboration: Fostering Integration of Information Literacy by Speaking the Language of Faculty," Association of College and Research Libraries National Conference (2013): 9-12.

11. Ignacio J. Ferrer-Vinent and Christy A. Carello, "Embedded Library Instruction in a FirstYear Biology Laboratory Course," Science \& Technology Libraries 28, no. 4 (2008): 325-51; Salome V. Brooks and Susan Bigelow, "Preparing Students for Research: Faculty/Librarian Collaboration in a Pre-doctoral Physical Therapy Research Course," Health Information \& Libraries Journal 32, 
no. 4 (2015): 332-38.

12. American Library Association, Information Literacy Competency Standards.

13. Jessame E. Ferguson, Teresa Y. Neely, and Kathryn Sullivan, "A Baseline Information Literacy Assessment of Biology Students," Reference E User Services Quarterly (2006): 61-71.

14. Ibid.

15. Ibid.

16. Ibid.

17. Laura I. Saunders, "Faculty Perspectives on Information Literacy as a Student Learning Outcome," Journal of Academic Librarianship 38 no. 4 (2012): 226-36.

18. Saunders, "Faculty Perspectives on Information Literacy," 232-33.

19. Ibid.

20. Saunders, "Faculty Perspectives on Information Literacy," 233.

21. ACRL, Framework for Information Literacy for Higher Education.

22. Ibid.

23. Elizabeth Spievak and Pamela Hayes-Bohanon, "Just Enough of a Good Thing: Indications of Long-Term Efficacy in One-Shot Library Instruction," Journal of Academic Librarianship 39, no. 6 (2013): 488-99.

24. Peggy A. Pritchard, "The Embedded Science Librarian: Partner in Curriculum Design and Delivery," Journal of Library Administration 50, no. 4 (2010): 373-96.

25. Ibid.

26. Brian Winterman, Carrie Donovan, and Rachel Slough, "Information Literacy for Multiple Disciplines: Toward a Campus-Wide Integration Model at Indiana University, Bloomington," Communications in Information Literacy 5, no. 1 (2011): 38-54.

27. Winterman, Donovan, and Slough, "Information Literacy for Multiple Disciplines," 43-47.

28. Winterman, Donovan, and Slough, "Information Literacy for Multiple Disciplines," 43.

29. Winterman, Donovan, and Slough, "Information Literacy for Multiple Disciplines," 47.

30. Justin E. Bekelman, Yan Li, and Cary P. Gross, "Scope and Impact of Financial Conflicts of Interest in Biomedical Research: A Systematic Review," JAMA 289, no. 4 (2003): 454-65.

31. Ibid.

32. Lisa Bero, “Industry Sponsorship and Research Outcome: A Cochrane Review," JAMA Internal Medicine 173, no. 7 (2013): 580-81.

33. ALA/ACRL/STS Task Force, Information Literacy Standards.

34. Kyle Siler, Kirby Lee, and Lisa Bero, "Measuring the Effectiveness of Scientific Gatekeeping," Proceedings of the National Academy of Sciences 112, no. 2 (2015): 360-65.

35. Michael J. LaCour, and Donald P. Green, "When Contact Changes Minds: An Experiment on Transmission of Support for Gay Equality," Science 346, no. 6215 (2014): 1366-69; Haruko Obokata, Teruhiko Wakayama, Yoshiki Sasai, Koji Kojima, Martin P. Vacanti, Hitoshi Niwa, Masayuki Yamato, and Charles A. Vacanti, "Stimulus-triggered Fate Conversion of Somatic Cells into Pluripotency," Nature 505, no. 7485 (2014): 641-47.

36. ACRL, Framework for Information Literacy for Higher Education.

37. Ibid.

38. Lev S. Vygotsky, "Mind in Society: The Development of Higher Mental Process" (Harvard University Press, 1978).

39. Ivan Orlansky, Retraction Watch, available online at www.retractionwatch.com [accessed 13 August 2016].

40. Peter Suber, Open Access (Cambridge, Mass.: MIT Press, 2012 ), 117.

41. John Bohannon, "Who's Afraid of Peer Review," Science 342, no. 6154 (2013): 60-65.

42. Declan Butler, "The Dark Side of Publishing," Nature 495, no. 7442 (2013): 433-34. 